\title{
Quality evaluation of IVM embryo and imprinting genes of IVM babies
}

\author{
Hiroaki Yoshida • Hiroyuki Abe • Takahiro Arima
}

Published online: 2 February 2013

(C) The Author(s) 2013. This article is published with open access at Springerlink.com

\begin{abstract}
Purpose Oxygen consumption rates of human embryos derived from in vitro matured (IVM) oocytes and controlled ovarian hyperstimulation $(\mathrm{COH})$ were compared with scanning electrochemical microscopy (SECM) non-invasively in order to answer why embryos from IVM oocytes have lower developmental potential. We also analyzed the epigenetic disorders for IVM babies born in our clinic.

Methods The oxygen consumption rate was calculated with the SECM system for different maturation stages of human oocytes, IVM and $\mathrm{COH}$ embryos. Blood from umbilical cords of IVM babies was collected to examine the imprinting genes.

Results There were no significant differences in oxygen consumption of embryos at each cleavage stage between IVM and $\mathrm{COH}$ (range $0.26-0.56 \times 10^{14} / \mathrm{mol} \mathrm{S}^{-1}$ ). There also was no abnormality found in expression of imprinting genes in IVM babies.

Conclusions There are no differences in terms of oxygen consumption between embryos derived from IVM and
\end{abstract}

Capsule There are no differences in oxygen consumption between embryos derived from IVM and $\mathrm{COH}$, and there was no imprinting gene disorder founded from the IVM babies.

Guest Editors: Ri-Cheng Chian and Jiayin Liu; Editor-in-Chief: David F. Albertiniti

H. Yoshida $(\square)$

Yoshida Ladies Clinic, Center for Reproductive Medicine,

Sendai, Japan

e-mail: hiroaki@yoshida-lc.jp

H. Abe

Department of Biochemical Engineering, Graduate School of Science and Engineering, Yamagata University, Yamagata, Japan

T. Arima

Environment and Genome Research Center, Tohoku University

School of Medicine, Sendai, Japan
$\mathrm{COH}$. There was no imprinting gene disorder founded from IVM babies.

Keywords IVM $\cdot$ Oocytes $\cdot$ Embryo $\cdot$ Oxygen $\cdot$ Epigenetics

\section{Introduction}

Since the first in vitro fertilization embryo transfer (IVF-ET) baby born [1], the field of assisted reproductive technology (ART) has progressed tremendously. A variety of ovulation inductions is developed to acquire more oocytes for IVF in order to improve the pregnancy rate. In late 1990s, in vitro maturation (IVM) of human oocytes has been applied clinically [2], and the first pregnancy and delivery of IVM baby from woman with polycystic ovary syndrome (PCOS) was reported in 1994 [3]. The advantage of IVM is to avoid side effect of ovarian stimulation, including ovarian hyperstimulation syndrome (OHSS), and to reduce the treatment cost and mental stress. However, IVM treatment showed poor embryo development and low pregnancy rate [4]. To evaluate oocytes and embryos accurately, several approaches have been made non-invasively $[5,6]$. We reported that mitochondria are important cell organelle producing ATP through respiration, which is essential for cellular activity and closely related to oxygen consumption [7, 8]. When mitochondria developed normally in the oocyte, based on animal model studies, it indicated that the developmental potential of embryos was improved when mitochondria developed normally in oocytes $[7,9]$. Therefore, an oocyte and embryo respiration measuring system has been developed using Scanning Electrochemical Microscopy (SECM).

The respirational measuring system was used with microelectrode as a sensor to analyze oxygen consumption by the oxygen reduction based on the spherical diffusion theory. This system can measure cell respiration with non- 
invasively and high-sensitively. Moreover, with the respiration activity as an index, it is capable of securely examining embryos and oocytes quality in a short time.

\section{The oxygen consumption of embryos from IVM and $\mathrm{COH}$}

Total of 253 embryos from IVM oocytes were measured for oxygen consumption rate individually. The average oxygen consumption of each early cleavage stage embryo are $0.34 \pm$ 0.1 at 4-cell stage, $0.37 \pm 0.1$ at 6 -cell stage, $0.4 \pm 0.2$ at 8 -cell stage, and $0.50 \pm 0.2 \mathrm{~F} \times 10^{14} / \mathrm{mol} \mathrm{S}^{-1}$ at 10 cell stage at same grade by Veeck classification [10]. There was no significant difference between IVM and COH. Specifically, IVM is $0.44 \mathrm{~F} \times 10^{14} / \mathrm{molS}^{-1}$, and $\mathrm{COH}$ is $0.34 \mathrm{~F} \times 10^{14} / \mathrm{molS}^{-1}$ respectively by comparison on day 3 embryos. There was also no significant difference in blastocyst development between IVM and $\mathrm{COH}$ based on oxygen consumption (Fig. 1). It may suggest that pregnancy rate may be predicted by selecting embryos for transfer with combination of morphological and respiration rate evaluation [11].

\section{Evaluation of physical and mental development of IVM babies as well as epigenetic expression}

There are few reports about the evaluation of IVM babies. We were able to examine 7 babies out of 52 pregnancies for physical and mental disorders, such as mode of delivery, weight, height, and apgar score (Table 1). There was no abnormal disorder in babies from 11 months to 4.7 years of age.

Genome imprinting is a genetic phenomenon controls the allele-specific gene expression, which is an inheritance process that only a certain allele from a parent (father or mother) is expressed selectively. Since the increase of imprinting disorder with ART is reported recently [12], IVMIVF may bring more imprinting disorders than normal IVF due to its necessity of mature culture process. DNA methylation has been considered the most important epigenetic modification in gametogenetic process for the establishment of imprint. Arima et al. [5, 13] identified the region of allelespecific human imprinted gene and analyzed DNA methylation. Among 8 imprinted genes, H19, GTL2, and ZDBF2 are paternal, and PEG1, PEG3, LIT1, ZAC, and SNRPN are maternal. Any disorder of methylation pattern was not observed in regulatory region of analyzed 8 imprinted genes of born babies at our clinic (Fig. 2-a, b).

\section{Discussions}

The morphological examination has been applied for quality evaluation of oocyte and embryo for a long time. However, if it is only by morphological approach, it might be difficult to increase embryo development and pregnancy rate. Thus, the evaluation technique noted embryo metabolism is developed for quality evaluation of oocyte and cleavage stage embryo [13], and embryo metabolic activity focused on nutrient consumption, such as glucose, pyruvic acid, and amino acid, was also studied [1, 14]. Cell oxygen consumption products ATP in a process of oxidative phosphorylation, and it is regarded as one of the evaluation criteria of embryo metabolic activity [3].

As a new method for embryo evaluation, Tesarik et al. [15] reported the case which is improved the blastocyst developmental rate and implantation rate using the sequence of pronuclear of nuclear after 24-h culture. However, the recent report using time-lapse cinematography by Mio et al. [16] proved that the sequence of pronucleolus is just a part of certain evaluation at dynamic changed using his system observation because the sequence moves variously in individual cleavage stage embryo. That is, nucleolus transfers the sequence dramatically in a process of the development.

The oxygen consumption rate was measured using mouse and rabbit embryos at first [17]. This study measured mouse blastocyst, human oocyte and blastocyst [17], and oxygen consumption by transform of hemoglobin from oxygen hemoglobin indirectly. After that, mammal embryo oxygen consumption rate was measured with parameter of various
Fig. 1 Comparison of embryo oxygen consumption rate (pronuclear stage, Day 3). a shows oxygen comparison of embryo at pronuclear stage between IVM and $\mathrm{COH}$; b shows oxygen comparison of embryo on day 3 between IVM and $\mathrm{COH}$. Also it shows whether the embryos developed to blastocysts or not based on oxygen comparison (a)

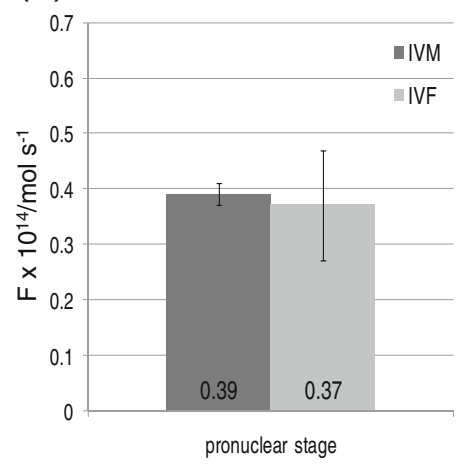

(b)

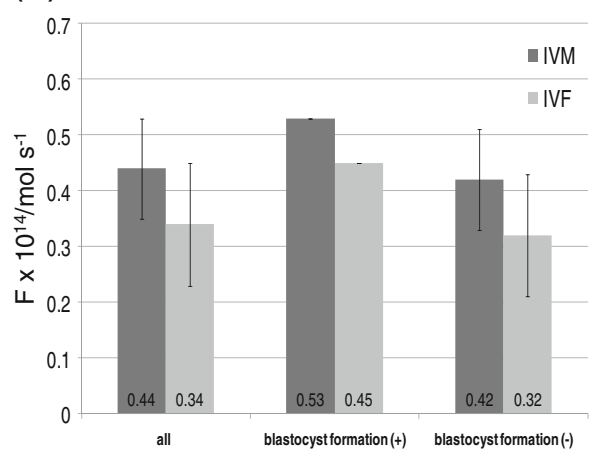


Table 1 Birth findings and prognosis of IVM babies born

\begin{tabular}{|c|c|c|c|c|c|c|c|c|}
\hline Patient & Outcomes & $\begin{array}{l}\text { Mode of } \\
\text { delivery }\end{array}$ & & Weight & Height & $\begin{array}{l}\text { Apgar. } \\
\text { score }\end{array}$ & $\begin{array}{l}\text { Cord } \\
\mathrm{pH}\end{array}$ & $\begin{array}{l}\text { Prognosis } \\
\& \text { others }\end{array}$ \\
\hline M.I & Delivery $(40 \mathrm{w}-6 \mathrm{~d})$ & Vaginal & M & $3102 \mathrm{~g}$ & $49.5 \mathrm{~cm}$ & $9 / 9$ & - & 1.8 y.o. N.P. \\
\hline M.S & $\begin{array}{l}\text { Delivery } \\
\quad \text { (twin, } 36 \mathrm{w}-1 \mathrm{~d} \text { ) }\end{array}$ & $\mathrm{C} / \mathrm{S}$ & $\mathrm{M} / \mathrm{F}$ & $2678 \mathrm{~g} / 2320 \mathrm{~g}$ & $46.2 \mathrm{~cm} / 44.5 \mathrm{~cm}$ & $9 / 9$ & - & 2 у.о. N.P. \\
\hline H.K & Delivery $(38 w-4 d)$ & Vaginal & M & $2810 \mathrm{~g}$ & $47 \mathrm{~cm}$ & $9 / 9$ & 7.438 & 4.7 у.о. N.P. \\
\hline E.S & Delivery (38 w-5 d) & Vaginal & M & $3070 \mathrm{~g}$ & $48 \mathrm{~cm}$ & $8 / 9$ & 7.114 & 1.6 у.о. N.P. \\
\hline M.S & Delivery $(41 \mathrm{w}-6 \mathrm{~d})$ & $\mathrm{C} / \mathrm{S}$ & M & $3966 \mathrm{~g}$ & $51 \mathrm{~cm}$ & $9 / 10$ & 7.29 & 1.4 у.о. N.P. \\
\hline J.Y & Delivery (39 w-4 d) & $\mathrm{C} / \mathrm{S}$ & M & $2964 \mathrm{~g}$ & $48.6 \mathrm{~cm}$ & $9 / 9$ & 7.23 & - \\
\hline M.K & Delivery $(40 \mathrm{w}-2 \mathrm{~d})$ & Vaginal & M & $3056 \mathrm{~g}$ & $47.8 \mathrm{~cm}$ & $8 / 8$ & 7.032 & 11 month \\
\hline
\end{tabular}

metabolic process data, for example, the method using diver by Magnusson [6], use of spectrophotometrics [18], method using fluorescent dye [19], and electrochemical technique [20]. More accurate and simple oxygen respiration measuring was required, so embryo respiration measuring system, which can measure single embryo oxygen respiration, was developed [7]. This system enables to greatly shorten the measuring time and improve the operability by the use of measuring plate with a conic micro well at the bottom. Also, this system achieved high-sensitive measuring of single cell
Fig. 2 a Analysis of methylation for imprinting genes from IVM babies; b Imprint gene Methylation assay with umbilical cord from IVM baby (a)

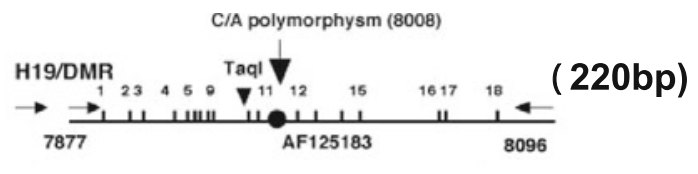

COBRA

Control

Taql

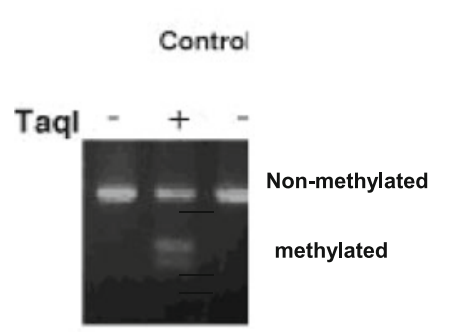

Non-methylated

methylated

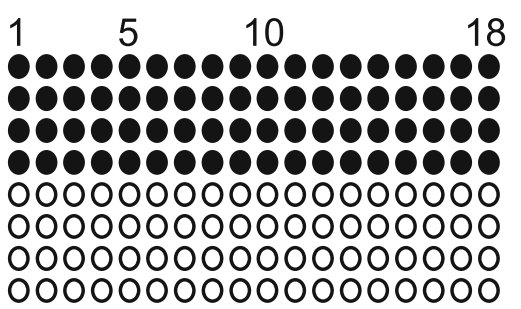

Paternal: H19, GTL2, ZDBF2

Maternal: PEG1, PGE3, LIT1, ZAC,SNRPN

(b)

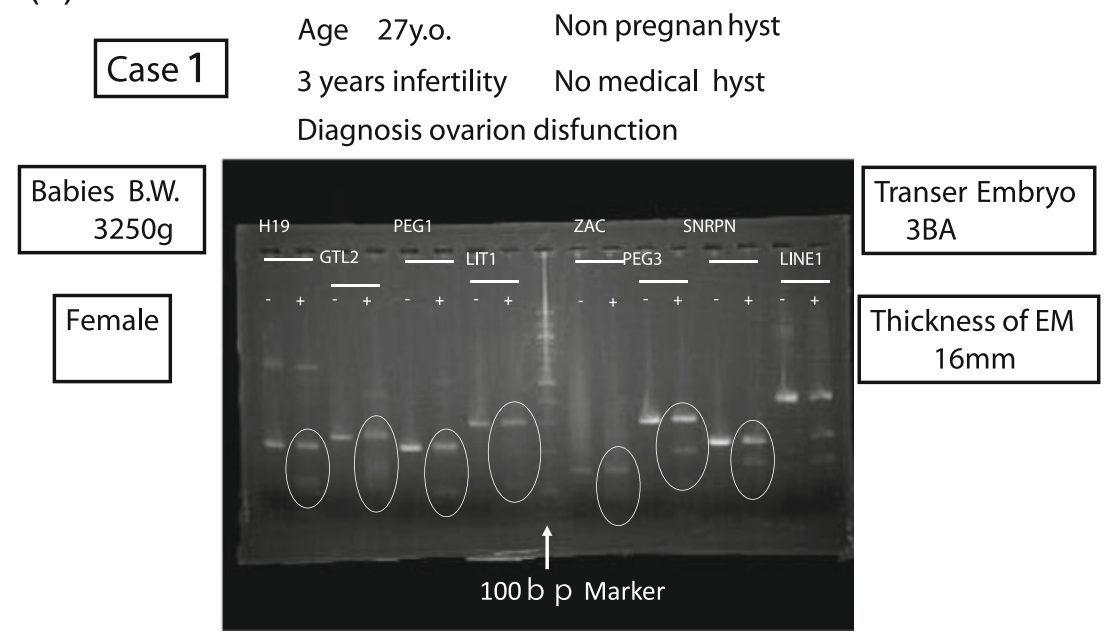


respiration, so eventually it can evaluate individual embryo quality with high-precision [7].

According to Abe report et al. [7, 9], respiration increase corresponds with mitochondrial development from morula to blastocyst stage in most of animal embryos, and the embryo with high consumption rate has a good viability and freezing ability. In addition, it is proved that the embryo with respiration rate above standard value is also high in pregnancy rate at transplant experiment after respiration measuring. These results demonstrate that consumption measuring is effective to evaluate embryo quality [7]. As for human embryos, it is evident there is a difference of respiration rate between embryos at same grade by Veeck classification, and embryo development needs respiration more than constant rate. Recently, we also found when the respiration rate increases in a group of thawing embryo, developmental rate for blastocyst and freezing ability for cryopreservation will be high.

Moreover, measuring consumption rate of single animal embryo by SECM system enables much detailed examination of metabolic capacity in a process of oocyte development. Abe et al. [7] reported that mitochondria distribution manner, the ATP amount of oocyte, and respiration ability of oocyte and cumulus alter prominently at pre or post maturation, and the respiratory activity is influenced with condition of culture medium. They also proved the oocyte respiration ability varies with the condition of adherent cumulus, and COC with high respiration activity increase maturation rate after oocyte maturation culture. Likewise, human oocyte respiration rate is significantly high at Grade 1 and 2, which are adhered with more than three layers of cumulus, and it influences the maturation, fertility, and embryo developmental rate thereafter. These results suggested that SECM is effective for quality evaluation of human oocytes. There is no significant difference of subsequent oocyte oxygen consumption rate between from $\mathrm{COH}$ and IVM, or any ages. Thus IVM embryo established as oocyte has same functions as $\mathrm{COH}$ oocyte.

Imprint disorder in ART was originally rare, but it is increasing with the development of technique in recent years. In the U.S, there is a report that the frequency of BeckwithWiedemann syndrome is $0.76 \%$ in a general group, whereas it is $4.1 \%$ (about 6 times higher) after ART [12]. In addition, it is reported that about $25 \%$ of male sperm under infertility treatment shows imprint disorder [13]. Since IVM requires maturation culture, the culture duration becomes longer than IVF, and it may bring an epigenetic transform; however, there is no epigenetic disorder of newborn babies from IVM process in our clinic. In any case, ART has still to be investigated to prove the safety in the future.

\section{Conclusions}

Embryo respiration measuring system based on SECM enables to measure the respiration of single human embryos. Combination of morphological evaluation and respiration rate may provide an effective barometer of embryo selection. IVM embryos have the same function as $\mathrm{COH}$ embryos after fertilization. None physical and mental disorders or defects in epigenetic genes were observed in IVM babies. It requires further study with more large numbers in the future.

Open Access This article is distributed under the terms of the Creative Commons Attribution License which permits any use, distribution, and reproduction in any medium, provided the original author(s) and the source are credited.

\section{References}

1. Rieger D, Loskutoff NM. Changes in the metabolism of glucose, puruvate, glutamine and Glycine and Glycine during maturation of cattle oocyte in vitro. J Reprod Fertil. 1994;100:257-62.

2. Boiso I, Veiga A, Edwards RG. Fundamentals of human embryonic for growth in vitro and the selection of high-quality embryos for transfer. Reprod Biomed Online. 2002;5:328-50.

3. Thompson JG, McNaughton C, Gasparrini B, McGowan LT, Tervit HR. Effect of inhibitors and uncuplers of oxidative phosphorylationduring compaction and blastulation of bovine embryos cultured in vitro. J Reprod Fertil. 2000;118:47-55.

4. Cha KY, Chian RC. Maturation in vitro of immature human oocytes for clinic use. Hum Reprod Update. 1991;4:103.

5. Takahiro A, Hisato K. Evaluation for epigenetic abnormality in infertile male sperm. Journal of Japan Society of Fertilization \& Implantation. 2009;38:409 (in Japanese).

6. Nilsson BO, Magnusson C, Widéhn S, Hillensjö T. Correlation between blastocyst oxygen consumption and trophoblasts cytoclome oxidase reaction at initiation of implantation of delayed mouse blastocysts. J Embryol Exp Morphol. 1982;71:75-82.

7. Abe H. A non-invasive and sensitive method for measuring cellular respiration with a scanning electrochemical microscopy to evaluate embryo quality. J Mamm Ova Res. 2007;24:70-8.

8. Overstorm EW, Duby RT, Dobrinsky J, Roche JF, Boland MP. Viability and oxidative metabolism of the bovine blastocyst (Abstract). Theriogenology. 1992;37:269.

9. Abe H, Shiku H, Aoyagi S, Matsue T, Hoshi H. Respiration activity of bovine embryos cultured in serum-free and serumcontaining media (Abstract). Reprod Fert Dev. 2005;17:215.

10. Veeck LL. Oocyte assessment and biological performance. Ann NY Acad Sci. 1988;541:259-95.

11. Utsunomiya T, Goto K, Nasu M, Kumasako Y, Araki Y, Yokoo T, et al. Evaluating the quality of human embryos with a measurement of oxygen consumption by scanning electrochemical microscopy. J Mamm Ova Res. 2008;25:2-7.

12. Manipalviratn S, DeCherney S, Segars J. Imprinting disorders and reproductive technology. Fert Steril. 2009;91:305-15.

13. Kobayashi H, Sato A, Otsu E, Hiura H, Tomatsu C, Utsunomiya T, et al. Aberrant DNA methylation of imprinted loci in sperm from oligospermic patients. Hum Mol Genet. 2007;16:2542-51.

14. Gopichandran N, Leese HJ. Metabolic characterization of the bovine blastocyst, inner cell mass, trophectoderm and blastocoel fluid. Reproduction. 2003;126:299-308. 
15. Tesalik J, Junca AM, Hazout A, Aubriot FX, Nathan C, CohenBacrie P, et al. Embryos with high implantation potential after intracytoplasmic sperm injection can be recognized by a simple, noninvasive examination of pronuclear morphology. Hum Reprod. 2000;6:1396-9.

16. Mio Y. Morphological analysis of human embryonic development using time lapse cinematography. J Mamm Ova Res. 2006;23:27-35.

17. Magnusson C, Hillensjö T, Hamberger L, Nilsson L. Oxygen consumption by human oocytes and blastocysts grown in vitro. Hum Reprod. 1986;1:183-4.
18. Donnay I, Leese HJ. Embryo metabolism during the expansion of the bovine blastocyst. Mol Reprod Dev. 1999;53:171-8.

19. Land SC, Porterfield DM, Sanger RH, Smith PJ. The selfreferencing oxygen-selective microelectrode detection of transmembrane oxygen flux from single cells. J Exp Biol. 1999;202:211-8.

20. Lopes AS, Larsen LH, Rmsing N, Løvendahl P, Räty M, Peippo J, et al. Respiration rates of individual bovine in vitro-produced embryos measured with a novel, non-invasive and highly sensitive micro sensor system. Reproduction. 2005;130:669-79. 